\title{
BMJ Open Effect of PIFR-based optimised inhalation therapy in patients recovering from acute exacerbation of chronic obstructive pulmonary disease: protocol of a prospective, multicentre, superiority, randomised controlled trial
}

To cite: Hua J, Zhang W, $\mathrm{CaO} \mathrm{H}$, et al. Effect of PIFRbased optimised inhalation therapy in patients recovering from acute exacerbation of chronic obstructive pulmonary disease: protocol of a prospective, multicentre, superiority, randomised controlled trial. BMJ Open 2020;10:e034804. doi:10.1136/ bmjopen-2019-034804

- Prepublication history and additional material for this paper are available online. To view these files, please visit the journal online (http://dx.doi. org/10.1136/bmjopen-2019034804).

Received 06 0ctober 2019

Revised 02 April 2020

Accepted 03 April 2020

Check for updates

(C) Author(s) (or their employer(s)) 2020. Re-use permitted under CC BY-NC. No commercial re-use. See rights and permissions. Published by BMJ.

For numbered affiliations see end of article.

Correspondence to

Dr Jing Zhang;

jingatlas@hotmail.com

\section{ABSTRACT}

Introduction Acute exacerbation (AE) is a major cause of disease progression and death in patients with chronic obstructive pulmonary disease (COPD), accounting for majority of medical expenditures. Correct inhalation therapy is effective in preventing AE attacks. However, inappropriate usage of dry powder inhaler, partially due to the unrecovered peak inhalation flow rate (PIFR) after acute exacerbation of COPD (AECOPD), results in increased risk of early treatment failure. Therefore, we designed a multicentre, randomised clinical trial to determine whether PIFR-based optimised inhalation therapy and training on inhaler usage at discharge could effectively reduce early treatment failure events.

Methods and analysis A total of 416 hospitalised patients just recovering from $A E C O P D$ will be recruited and equally randomised into the PIFR group and the control group at a 1:1 ratio. The PIFR group will receive additive support before discharge, including choice of PIFR-guided inhaler and education on its usage. PIFR is measured by InCheck DIAL. In comparison, the control group will receive inhalers based on judgement of the respiratory physician. The primary outcome of the study is 30-day treatment failure rate. Other endpoints include PIFR, error rate of inhalation device use, satisfaction with inhalation devices, 30-day mortality, 90-day mortality, symptoms and quality of life of patients, and COPD-related treatment costs. Ethics and dissemination The trial has been approved by the Ethics Committee of Zhongshan Hospital of Fudan University (B2019-142). Participants will be screened and enrolled from hospitalised patients with AECOPD by clinicians, with no public advertisement for recruitment. After the trial has completed, the results will be reported to the public through conference presentations and peerreviewed journals.

Trial registration number NCT04000958.

\section{INTRODUCTION}

Chronic obstructive pulmonary disease (COPD) is a chronic inflammatory disease
Strengths and limitations of this study

To our knowledge, this is the first multicentre, randomised trial designed to study the efficacy of peak inhalation flow rate (PIFR)-based inhaler prescription in preventing short-term re-exacerbations in patients recovering from severe acute exacerbation of chronic obstructive pulmonary disease.

- InCheck DIAL is used to measure PIFR and objectively evaluate the capacity of using dry powder inhalers.

- Participants will be trained on inhaler techniques and on achieving optimal inhalation therapy.

- Inhalers studied in this trial include Turbuhaler, HandiHaler, Respimat and pressure metered dose inhalers.

- A limitation of the study is its single-blind design, which would yield bias, although blind evaluation is adopted to minimise bias.

characterised by irreversible airflow limitation. It is the third leading cause of death and causes heavy socioeconomic burden worldwide. ${ }^{1}$ In China, COPD is also a serious challenge, with a prevalence of $8.6 \%$ among adults and with high mortality. ${ }^{2}$ Direct medical costs of COPD range from US $\$ 72$ to US $\$ 3565$ per capita per year, accounting for 33\%-118\% of the average annual income of Chinese people. ${ }^{3}$ As an important event throughout the course of COPD, acute exacerbation (AE) could accelerate decline in spirometry values and directly cause death, and could bring about huge health expenditure. ${ }^{4}$

Inhalation drugs, such as inhaled corticosteroid (ICS), long-acting $\beta 2$ agonists (LABA) and long-acting muscarinic antagonists (LAMA), are the core pharmaceutical 
therapy in the management of stable COPD. ${ }^{5}$ However, inappropriate usage of inhalers is common in patients with chronic airway diseases, such as insufficient inspiratory force and no breath holding (or holding breath for less than $3 \mathrm{~s}) .{ }^{67}$ Previous studies showed that errors in usage of inhalers were significantly associated with poor outcomes (such as frequent exacerbations) and increased medical expenditure. ${ }^{8}$ Commonly used inhalers are classified into four types, with different characteristics: pressure metered dose inhaler (pMDI), dry powder inhalers (DPIs), soft mist inhalers and nebulisers. ${ }^{9}$ The use of pMDIs is relatively complex, requiring patients to slowly breathe in and ensuring coordination in many other processes to achieve a clinically effective dose. In comparison, the use of DPIs is simple, but requires increased inspiratory force to overcome the device's internal resistance. ${ }^{10}$ Several in vitro studies have demonstrated that the efficacy of DPI is dependent on the inspiratory flow rate.

When the patient's peak inhalation flow rate (PIFR) is less than a certain threshold required by the DPI device $(60 \mathrm{~L} / \mathrm{min}$ measured at no resistance $),{ }^{11}$ the DPI device releases a reduced dose of the drug and generates aerodynamically large drug particles that are inappropriate to meet therapeutic needs. Moreover, several studies demonstrated that insufficient PIFR in the stable COPD period was associated with poor prognosis when patients improperly used DPI. ${ }^{12} 13$ It should be noted that expiratory flow parameters are not linearly correlated with inspiratory flow rate, suggesting that postbronchodilator forced expiratory volume in $1 \mathrm{~s}\left(\mathrm{FEV}_{1}\right)$ is not a suitable predictor of PIFR. Other risk factors for early recurrence of acute exacerbation of COPD (AECOPD) include age, Global Initiative for Chronic Obstructive Lung Disease (GOLD) grade, AE frequency in the previous year, pleural effusion, use of accessory respiratory muscles, non-invasive mechanical ventilation, controlled oxygen therapy and length of hospital stay, while inhaled LABA and ICS are protective factors. ${ }^{14}$

Short-term re-exacerbation is a prominent problem among patients hospitalised for AECOPD, with a 30-day readmission rate of $16 \%-20 \% .{ }^{15}{ }^{16}$ Many patients with COPD do not have enough PIFR to reach the threshold that DPI devices required both in the stable period (nearly $20 \%)^{17}$ and in the AE period (based on some small sample studies), ${ }^{13} 18$ influencing the effects of inhaled drugs on preventing AE recurrences. Moreover, the assessment of patients' PIFR and their ability to use inhaler devices is not integrated into the clinical pathway of discharge for patients hospitalised for AECOPD. Clinicians are still inclined to choose the type of inhalers that patients used before admission.

We speculate that the PIFR of patients in the AE recovery period does not return to their baseline levels before $\mathrm{AE}$, and untrained patients are more likely to use the inhalers incorrectly. Neglect of evaluation of inhalers might result in treatment failure and early re-exacerbation due to ineffective use of inhaled drugs. However, there is a lack of studies demonstrating whether the choice of inhalers based on the PIFR count could reduce the risk of shortterm re-exacerbation in patients with AECOPD. Furthermore, although some research showed that inappropriate use of inhalers was associated with poor prognosis, ${ }^{78}$ it remains unclear whether training patients to correctly use inhalers could reverse poor outcomes.

Therefore, we plan to perform this clinical trial to prospectively determine whether an optimised inhaled drug administration based on PIFR and training with InCheck DIAL could reduce the rate of treatment failure and improve the prognosis of patients hospitalised for AECOPD. Our hypothesis is that AECOPD treatment failure rate is related to improper inhaler selection and lack of education on use of inhalers among patients.

\section{METHODS AND ANALYSIS \\ Overview}

This is a multicentre, single-blind, superiority, randomised clinical trial where patients hospitalised for AECOPD are randomly assigned into two groups at a 1:1 ratio: the PIFR group and the control group. Compared with the control group, the PIFR group will receive additive support before discharge, including PIFR-guided choice of inhaler and education on inhaler use. The primary outcome is 30-day treatment failure rate. Other endpoints include symptoms and quality of life of patients, error rate of inhalation device use, satisfaction with inhalation device, PIFR, 30-day mortality, 90-day mortality, and COPD-related treatment costs.

Patient enrolment, intervention and follow-up are performed at the Zhongshan Hospital of Fudan University, Shanghai Jing'an District Central Hospital, Shanghai Qingpu District Central Hospital and the North Branch of Shanghai Ninth People's Hospital in China. The study is expected to last for 2 years. Recruitment of participants has started in November 2019.

\section{Inclusion criteria}

All patients with a diagnosis of COPD and hospitalisation for $\mathrm{AE}$ will be screened. $\mathrm{COPD}$ and $\mathrm{AE}$ are defined according to the criteria of the Expert Consensus on Acute Exacerbation of Chronic Obstructive Pulmonary Disease in the People's Republic of China-2014 Edition. ${ }^{4}$ Briefly, AECOPD is defined as a sudden worsening of respiratory symptoms requiring additional treatment (typical manifestations include dyspnoea, aggravated cough, increased sputum volume and/or sputum purulence) and are not explained by normal day-to-day variations. ${ }^{4} 19$

Patients will be included if all of the following criteria are met: (1) aged 40-80 years old; (2) deteriorated respiratory symptoms being controlled and meeting the discharge criteria after standard treatment of 5-7 days for AECOPD; (3) a recorded spirometry measured during the stable period, with postbronchodilator $\mathrm{FEV}_{1} /$ forced vital capacity $<70 \%$ and $\mathrm{FEV}_{1} \%$ predicted value $<80 \%$; and (4) signed informed consent form. 
Standard treatment during hospitalisation includes atomised or inhaled bronchodilators, broad-spectrum antibiotics and corticosteroids (oral or intravenous glucocorticoids daily equivalent to the $40-50 \mathrm{mg}$ dose of prednisone, or Pulmicort $2 \mathrm{mg}$ atomisation two times per day).

The discharge criteria are as follows: (1) the physician is confident that the patient can manage successfully at home; (2) either LABA and/or LAMA can be used for maintenance with or without ICS, and the frequency of short-acting inhaled $\beta 2$ receptor agonists is less than every 4 hours; (3) the patient, if previously ambulatory, is able to walk across the room; (4) the patient is able to eat and sleep without frequent awakening due to dyspnoea; (5) the patient achieves clinically stable status lasting for 12-24 hours; and (6) values of arterial blood gases have been stable for $12-24$ hours. ${ }^{4}$

\section{Exclusion criteria}

Exclusion criteria include the following: (1) already using home nebulisation therapy due to severe condition; (2) concomitant with asthma, interstitial lung disease, bronchiectasis, pulmonary embolism and other lung diseases; (3) with comorbidities including hypertension, heart diseases, chronic liver and kidney diseases, diabetes, chronic gastrointestinal diseases and malignant tumours, and is critically ill; (4) suffering from cognitive impairment or not cooperating with the study due to poor mental state; and (5) with PIFR less than $20 \mathrm{~L} / \mathrm{min}$.

\section{Sample size}

We plan to recruit 416 hospitalised patients with AECOPD whose deteriorated symptoms are relieved after 5-7 days of standard therapy. The sample size was calculated using PASS V.15.0 (Power Analysis and Sample Size Software, 2017; NCSS, Kaysville, Utah, USA) to ensure statistical power. Several studies have found that $30 \%-47 \%$ of patients hospitalised for AECOPD had a PIFR $<60 \mathrm{~L} /$ min prior to discharge. ${ }^{5}{ }^{10}$ For the control group, 30-day treatment failure rate after hospitalisation for AECOPD is approximately $20 \%$, according to the literature and our retrospective cohort study. ${ }^{15} 16$ However, our preliminary research suggests 30 -day treatment failure rate is $10 \%$ in the PIFR group. Thus, the expected effect size of superiority is around $10 \%$ between the two groups. The ratio of the number of people in the two groups is 1: 1. A significant two-sided $\mathrm{p}$ value is set at 0.05 and the power is set at $80 \%$. Considering potential dropout risks (5\%), 208 patients per group will be recruited, totalling 416 participants.

\section{Study outline}

The flow chart of the study design is shown in figure 1 .

The study will recruit 416 patients with AECOPD. After enrolment, the participants will be divided into the PIFR group and the control group at a 1:1 ratio. All participants in the two groups will receive standard treatment for AECOPD as described during the hospitalised period and will be given predesigned medications at discharge.
At discharge, all patients will be prescribed with commercial ICS/LABA combination, including either Symbicort Turbuhaler (budesonide/formoterol, 160/4.5 $\mu \mathrm{g}$ two times per day, AstraZeneca) or Foster pressure pMDI (beclomethasone/formoterol, 100/6 $\mu$ g two puffs two times per day, Chiesi Farmaceutici SpA). For patients with more respiratory symptoms during the stable period (modified Medical Research Council (mMRC) $\geq 2$ and COPD Assessment Test (CAT) $\geq 10$ ), Spiriva HandiHaler (18 $\mu$ g once a day) or Spiriva Respimat ( $2.5 \mu \mathrm{g}$ twice a day, Boehringer Ingelheim Pharma \& Co KG) will be given in combination with ICS/LABA.

As for inhalers, participants in the control group will be given DPI or pMDI with a spacer based on judgement of the attending physician, while participants in the PIFR group will receive education on use of inhaler and additive support for evaluation of PIFR at the time of discharge. Attending physicians will show the proper use of inhalers and correct some common mistakes to patients in the PIFR group.

For the PIFR group, PIFR is measured by InCheck DIAL (Clement Clarke International, Harlow, UK and Alliance Tech Medical), which is designed to measure inspiratory flow and simulate the 'internal resistance' of common inhalers. The numerical values of PIFR provide reference for the attending physician to guide patients in improving their inspiratory techniques, such as increasing or decreasing inspiration forces, which is helpful to achieve a flow rate consistent with clinical efficacy. The coloured 'flow' icons show the clinically effective flow ranges for each inhaler device. The InCheck DIAL is accurate up to $\pm 10 \%$ or $10 \mathrm{~L} / \mathrm{min}$ and is a low-range inspiratory flow metre (15-120 L/min) with options for resistance ranging from high to low, shown by the coloured 'flow' icons calibrated to enable the measurement of airflow when the patient is using a different inhaler. When measuring PIFR, we will set the resistance of the InCheck DIAL to 'Zero' and to 'Med High' in line with pMDI and Turbuhaler, respectively. Before the measurement, patients will be trained on how to use the InCheck DIAL correctly. When patients' PIFR steadily reached the maximum value, the PIFR will be measured three times, the average of which will be considered the final result. If PIFR is less than $60 \mathrm{~L} / \mathrm{min}$ (measured without a resistance), the patients will be given the pMDI with spacer. Otherwise, they will be prescribed with the DPI. Patients using either pMDI or DPI will be taught on how to use the device on the spot and can access an educational video via a WeChat public account at any time.

Moreover, the InCheck DIAL is also a training device for inhalation muscles and helps to improve patients' ability to use inhalers. When used for training of inspiratory muscles, the resistance threshold of InCheck DIAL is set according to the type of inhalers used by the patient.

\section{Study steps}

Researchers collect baseline information from participants on the day of enrolment and provide interventions 


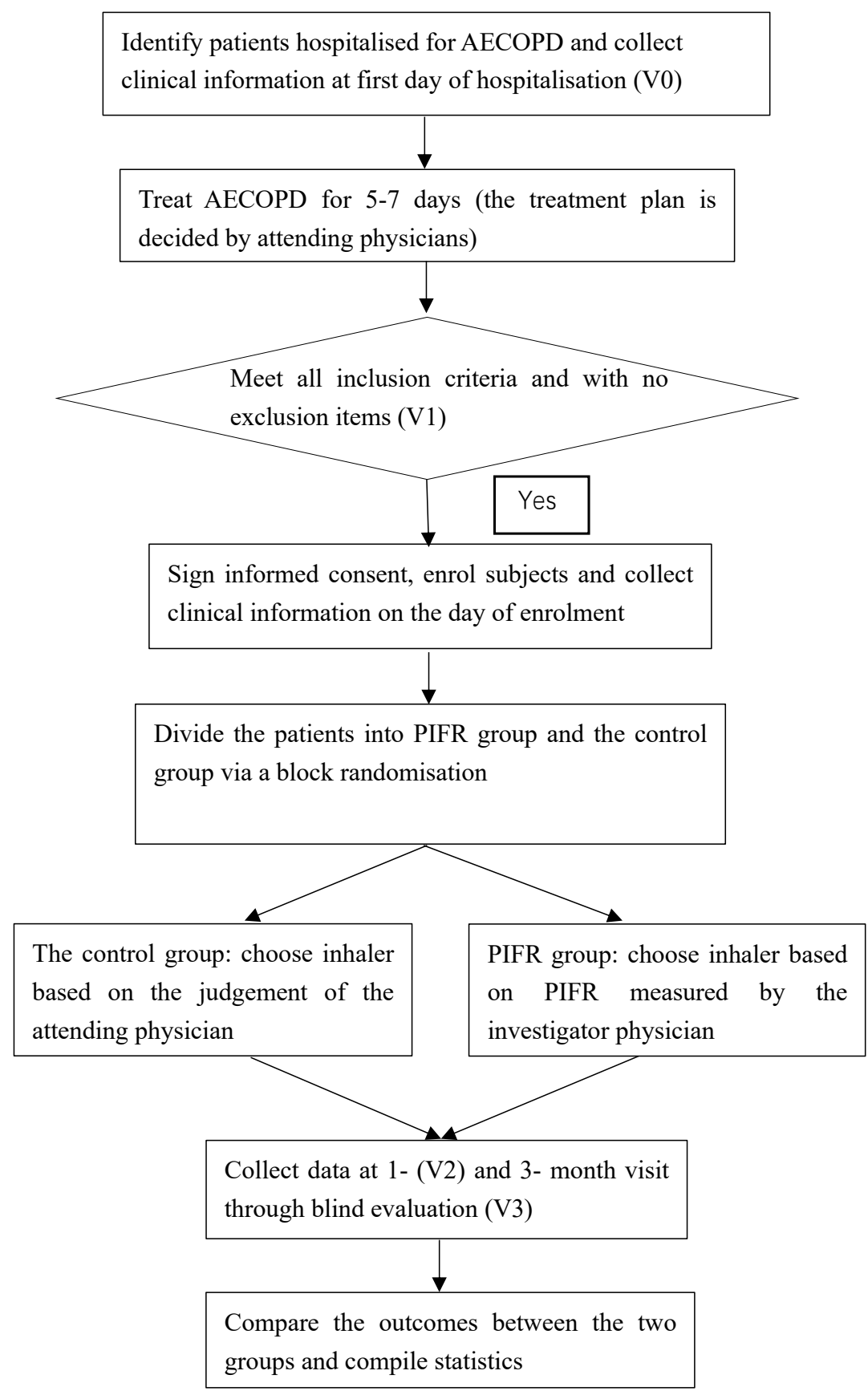

Figure 1 Flow chart of the study. Patients' screening, recruitment, intervention, visits and data processing are described in the figure. Visit 0 (V0), visit 1 (V1), visit 2 (V2) and visit 3 (V3) are timepoints to collect data. AECOPD, acute exacerbation of chronic obstructive disease; PIFR, peak inspiratory flow rate.

to patients with $\mathrm{COPD}$ recovering from $\mathrm{AE}$ at the time of discharge. After discharge, all participants will be followed up for 3 months and will be asked for two separate visits at 1 and 3 months.

Table 1 shows the data that need to be collected at each visit. Baseline information in the stable period includes demographics, clinical characteristics, evaluation of respiratory symptoms and quality of life at stable phase, PIFR, chest imaging (X-ray or CT), and echocardiography or
ECG at stable phase. Demographics include age, gender, age, height, weight, ethnicity, occupation (number of years of work), marital status, family address and so on. Clinical characteristics include disease history, history of drug sensitivity, history of vaccination, family disease history, current medical status, comorbidities, medications and so on. Respiratory symptoms are assessed by the mMRC Dyspnea Scale and CAT, while quality of life is evaluated by the St George's Respiratory Questionnaire 
Table 1 Data collected at each visit

\begin{tabular}{|c|c|c|c|c|}
\hline & \multirow{2}{*}{$\begin{array}{l}\text { Visit } 0 \\
\\
\text { Hospitalisation } \pm 1 \text { day }\end{array}$} & \multirow{2}{*}{$\begin{array}{l}\text { Visit } 1 \\
\text { At the time } \\
\text { of discharge } \\
\text { (meet discharge } \\
\text { standards ) }\end{array}$} & \multirow{2}{*}{$\begin{array}{l}\text { Visit } 2 \\
\begin{array}{l}1 \text { month after } \\
\text { discharge }\end{array}\end{array}$} & \multirow{2}{*}{$\begin{array}{l}\text { Visit } 3 \\
\begin{array}{l}3 \text { months after } \\
\text { discharge }\end{array}\end{array}$} \\
\hline & & & & \\
\hline Basic information & $\sqrt{ }$ & & & \\
\hline Information on COPD at stable phase & $\sqrt{ }$ & & & \\
\hline Liver and kidney function & $\sqrt{ }$ & $\sqrt{ }$ & & \\
\hline Electrolytes & $\sqrt{ }$ & $\sqrt{ }$ & & \\
\hline $\mathrm{C}$ reactive protein & $\sqrt{ }$ & $\sqrt{ }$ & & \\
\hline Procalcitonin & $\sqrt{ }$ & $\sqrt{ }$ & & \\
\hline Brain natriuretic peptide & $\sqrt{ }$ & $\sqrt{ }$ & & \\
\hline mMRC score & $\sqrt{ }$ & $\sqrt{ }$ & $\sqrt{ }$ & $\sqrt{ }$ \\
\hline SGRQ score & & $\sqrt{ }$ & $\sqrt{ }$ & $\sqrt{ }$ \\
\hline Drug for COPD & Stable phase & AE phase & Stable phase & Stable phase \\
\hline PIFR & & $\sqrt{ }$ & $\sqrt{ }$ & $\sqrt{ }$ \\
\hline Prognosis & & & $\sqrt{ }$ & $\sqrt{ }$ \\
\hline Pulmonary function & & $\sqrt{ }$ & $\sqrt{ }$ & $\sqrt{ }$ \\
\hline \multicolumn{5}{|l|}{ Echocardiography at stable phase } \\
\hline \multicolumn{5}{|l|}{ CT at stable phase } \\
\hline
\end{tabular}

AE, acute exacerbation; CAT, COPD Assessment Test; COPD, chronic obstructive pulmonary disease; mMRC, modified Medical Research Council Dyspnea Scale; PIFR, peak inhalation flow rate; SGRQ, St George's Respiratory Questionnaire.

(SGRQ). PIFR and routine laboratory tests for AE patients (eg, blood routine, $\mathrm{C}$ reactive protein, liver and kidney function, blood electrolytes, B-type natriuretic peptide, D-dimer) were also recorded.

At 1 and 3 months, patients are required to have an outpatient department visit for assessment of the effects of intervention and to collect some data including CAT score, mMRC score, SGRQ score, PIFR, spirometry, error rate of inhalation device use, satisfaction with inhalation devices and COPD-related medications. To reinforce adherence, patients and their relatives will be contacted in advance by telephone to confirm the dates of evaluation. If it is inconvenient for the patient to come to the hospital, researchers will collect the abovementioned information as much as possible via phone.

\section{Outcomes}

The primary endpoint is 30-day treatment failure rate of AECOPD. Treatment failure means AECOPD recurrence resulting in an emergency visit, admission or need for intensified medication.
Secondary outcomes include PIFR, error rate of inhalation device use, satisfaction with inhalation devices, 30-day mortality, 90-day mortality, symptoms and quality of life of patients, and COPD-related treatment costs.

Patients' satisfaction with inhalation devices will be assessed by the Feeling of Satisfaction with Inhaler (FSI10) questionnaire. The FSI-10 questionnaire is supposed to be completed by the patients themselves, and has been widely applied to assess patients' opinions about inhalers in terms of ease of use, portability and usability. ${ }^{20}$ The symptoms of patients are evaluated by CAT and mMRC, while quality of life is evaluated by SGRQ.

PIFR is measured by InCheck DIAL (Clement Clarke International and Alliance Tech Medical) under the guidance of respiratory physicians. Some common errors in the usage of different inhalation devices are described in table $2 .^{67}$

\section{Randomisation and blinding}

The participants will be assigned into two groups at a 1:1 ratio using a random number table generated by IBM 
Table 2 Common errors in the usage of different inhalation devices

\begin{tabular}{|c|c|c|c|}
\hline Turbuhaler & HandiHaler/Accuhaler & pMDI & Respimat \\
\hline $\begin{array}{l}\text { Cover is not removed or not } \\
\text { covered properly. }\end{array}$ & $\begin{array}{l}\text { Cover is not removed or not covered } \\
\text { properly. }\end{array}$ & $\begin{array}{l}\text { Cover is not removed or not } \\
\text { covered properly. }\end{array}$ & $\begin{array}{l}\text { Cover is not removed or not } \\
\text { covered properly. }\end{array}$ \\
\hline $\begin{array}{l}\text { Dose is reduced due to patients } \\
\text { shaking or tilting the device } \\
\text { during preparation. }\end{array}$ & - & & $\begin{array}{l}\text { The device is not installed } \\
\text { correctly before use. }\end{array}$ \\
\hline Device is not held upright. & - & Device is not held upright. & - \\
\hline Inhalation force is insufficient. & Inhalation force is insufficient. & $\begin{array}{l}\text { Patient does not inhale deeply } \\
\text { and slowly. }\end{array}$ & $\begin{array}{l}\text { Patient does not inhale deeply } \\
\text { and slowly. }\end{array}$ \\
\hline $\begin{array}{l}\text { Patient does not tilt his/her } \\
\text { head to make his/her chin } \\
\text { slightly upturned. }\end{array}$ & $\begin{array}{l}\text { Patient does not hold his/her head in a } \\
\text { vertical position. }\end{array}$ & $\begin{array}{l}\text { Patient does not tilt his/her } \\
\text { head to make his/her chin } \\
\text { slightly upturned. }\end{array}$ & $\begin{array}{l}\text { Patient does not point the } \\
\text { inhaler towards the back of } \\
\text { throat. }\end{array}$ \\
\hline- & $\begin{array}{l}\text { Patient does not turn his/her head away } \\
\text { from the device's mouthpiece before } \\
\text { exhalation. }\end{array}$ & $\begin{array}{l}\text { Patient exhales into the device } \\
\text { before the next inhalation. }\end{array}$ & $\begin{array}{l}\text { Patient covers the air entries } \\
\text { while inhaling. }\end{array}$ \\
\hline $\begin{array}{l}\text { Patient does not seal the } \\
\text { mouthpiece with his/her lips. }\end{array}$ & $\begin{array}{l}\text { Patient did not place the mouthpiece in his/ } \\
\text { her mouth nor closed his/her lips. }\end{array}$ & $\begin{array}{l}\text { Patient does not seal the } \\
\text { mouthpiece with his/her lips. }\end{array}$ & $\begin{array}{l}\text { Patient does not seal the } \\
\text { mouthpiece with his/her lips. }\end{array}$ \\
\hline NA & NA & $\begin{array}{l}\text { Patient does not inhale them in } \\
\text { sync with the drug releasing. }\end{array}$ & $\begin{array}{l}\text { Patient does not inhale them in } \\
\text { sync with the drug releasing. }\end{array}$ \\
\hline $\begin{array}{l}\text { Patient does not hold breath (or } \\
\text { hold breath less than } 3 \mathrm{~s} \text { ). }\end{array}$ & $\begin{array}{l}\text { Patient does not hold breath (or hold breath } \\
\text { less than } 3 \mathrm{~s} \text { ). }\end{array}$ & $\begin{array}{l}\text { Patient does not hold breath (or } \\
\text { hold breath less than } 3 \mathrm{~s} \text { ). }\end{array}$ & $\begin{array}{l}\text { Patient does not hold breath } \\
\text { (or hold breath less than } 10 \mathrm{~s} \text { ). }\end{array}$ \\
\hline $\begin{array}{l}\text { Patient does not cover the lid } \\
\text { and wait for } 30-60 \text { s for the } \\
\text { second dose. }\end{array}$ & $\begin{array}{l}\text { Patient does not dispose of the capsule and } \\
\text { cover the lid on the device. }\end{array}$ & $\begin{array}{l}\text { Patient does not exhale and } \\
\text { wait for } 30-60 \text { s before the } \\
\text { second puff. }\end{array}$ & $\begin{array}{l}\text { Patient does not inhale twice } \\
\text { to achieve the total daily } \\
\text { dosage. }\end{array}$ \\
\hline
\end{tabular}

NA, not applicable; pMDI, pressure metered dose inhaler.

SPSS Statistics V.23. Randomisation was performed by an independent researcher who will not participate in other research procedures. To maximise the objectivity and reliability of our study, single-blind and allocation concealment are adopted. Sealed envelopes containing an allocation number are distributed to attending physicians in advance to achieve allocation concealment, and they will not know the allocation group until giving intervention. Other researchers responsible for data collection and follow-up are not informed of which group the patient has been assigned to. Patients and their relatives are blinded to allocation during the whole process, and are only informed that they are participating in a study of COPD discharge plan. In addition, statistical analysis will be performed by an independent statistician, who will also be blinded to the group labels.

\section{Statistical analysis}

Statistical analysis data sets

- Modified intent-to-treat set: subjects who have undergone randomisation and interventions, and carry out primary endpoint evaluation.

- Safety set: subjects who are randomised, undergo the intervention and with safety evaluation data.

\section{Statistical analysis methods}

Statistical analyses will be performed using IBM SPSS Statistics V.22. Continuous variables are described as mean (SD) or median (IQR), while categorical variables are described as frequency and percentage. A two-tailed $\mathrm{p}$ value $<0.05$ is considered statistically significant. Student's t-tests or Mann-Whitney test, depending on normality and homogeneity of variance, was used to compare continuous variables between the two groups, including PIFR, CAT score, mMRC score, SGRQ score and COPDrelated treatment costs. For discrete variables, such as 30-day treatment failure rate, error rate of inhalation device use, satisfaction with inhalation devices, 30-day mortality and 90-day mortality, $\chi^{2}$ test, Fisher's exact test or Cochran-Mantel-Haensel (CMH) $\chi^{2}$ test will be applied for comparison. To rule out the influence of confounding factors and identify optimal subpopulation, subgroup analysis will be performed based on exacerbation history and GOLD grade.

\section{Patient and public involvement}

Patients or the public were not involved in the design, or conduct, or reporting, or dissemination of our research. The results will be available to the public if necessary. 


\section{Ethics and dissemination}

This trial has been approved by the Ethics Committee of Zhongshan Hospital of Fudan University (B2019-142). In this study, diagnosis and treatment will be performed in accordance with the routine management of COPD. Neither additional drug intervention nor invasive examination and charges will be needed. Therefore, the study is relatively safe with minimal additional risks. Participants will be screened and recruited from hospitalised patients by physicians, with no public advertisement for recruitment. All participants are supposed to sign an informed consent. A blank copy of the original consent form is provided and shown as an online supplementary document. All information from the participants will be kept private and will not be provided to any company or institution. The results will be disseminated through peerreviewed journals and conference presentations.

\section{DISCUSSION}

DPI drug delivery depends on the inherent resistance of the inhaler and the PIFR of the patient. PIFR value is determined by an individual's subjective effort as well as his/her respiratory muscle force, which may be decreased in patients with COPD due to airway stenosis, lung hyperinflation, hypoxaemia and muscle wasting. As a breath-actuated inhaler, DPI requires patients to create enough turbulent forces to disaggregate the powder into respirable particles which can reach the lower respiratory tract. Patients with a relatively high PIFR $(>60 \mathrm{~L} / \mathrm{min})$ enable DPIs to release a sufficient amount of powder and disaggregate the drug to achieve sufficient drug deposition in the lung.

Sharma and colleagues ${ }^{10}$ reported that $31.7 \%$ of hospitalised patients for AECOPD had PIFR less than $60 \mathrm{~L} / \mathrm{min}$ at the time of discharge. Patients with a PIFR less than $60 \mathrm{~L} / \mathrm{min}$ have been considered not able to effectively inhale medications using a DPI into their lower respiratory tracts, while a PIFR less than $30 \mathrm{~L} / \mathrm{min}$ was insufficient. ${ }^{21}{ }^{22}$ For lack of availability of long-acting bronchodilators with pMDI, most Chinese clinicians routinely prescribe DPIs to patients recovering from AECOPD without measuring their PIFR values. Inappropriate inhaler selection may result in AECOPD treatment failure. To our knowledge, it remains unclear whether treatment failure rate is negatively related to improper inhaler description. A suitable inspiratory flow rate helps to improve treatment efficacy. In addition to appropriate inhaler selection, participants in the PIFR group also receive inhaler training to help them master the proper way of inhalation.

Our research proposed to measure the PIFR of patients recovering from AECOPD using InCheck DIAL to guide the choice of inhalers and training on inhalation techniques. The aim of this study is to determine whether treatment failure rate of patients just recovering from AECOPD could be reduced by the optimised inhalation therapy based on PIFR, which is measured against the simulated airway resistance. We anticipate that the positive results of this study will provide evidence for improving discharge protocols for AECOPD by including PIFR evaluation.

\section{Author affiliations}

${ }^{1}$ Department of Pulmonary and Critical Care Medicine, Zhongshan Hospital Fudan University, Shanghai, China

${ }^{2}$ Department of Biostatistics, Fudan University, Shanghai, China

${ }^{3}$ Department of Pulmonary, Shanghai Jing'an District Central Hospital, Shanghai, China, Shanghai, China

${ }^{4}$ Department of Pulmonary, Shanghai Qingpu District Central Hospital, Shanghai, China

${ }^{5}$ Department of Pulmonary, North Branch of Shanghai Ninth People's Hospital, Shanghai, China

Contributors $\mathrm{JH}$ and JZ planned the study. WZ planned the statistical analysis methods. All authors contributed to the design and development of the trial $(\mathrm{JH}$, JZ, WZ, H-FC, C-LD, J-YM and Y-HZ). JH drafted the manuscript. JZ, H-FC, C-LD, $\mathrm{J}-\mathrm{YM}$ and $\mathrm{Y}-\mathrm{HZ}$ contributed to the revision of the manuscript. All authors read and approved the final manuscript.

Funding The authors have not declared a specific grant for this research from any funding agency in the public, commercial or not-for-profit sectors.

Competing interests None declared.

Patient and public involvement Not required.

Patient consent for publication Not required.

Provenance and peer review Not commissioned; externally peer reviewed.

Open access This is an open access article distributed in accordance with the Creative Commons Attribution Non Commercial (CC BY-NC 4.0) license, which permits others to distribute, remix, adapt, build upon this work non-commercially, and license their derivative works on different terms, provided the original work is properly cited, appropriate credit is given, any changes made indicated, and the use is non-commercial. See: http://creativecommons.org/licenses/by-nc/4.0/.

ORCID iD

Jianlan Hua http://orcid.org/0000-0001-5832-5893

\section{REFERENCES}

1 Lozano R, Naghavi M, Foreman K, et al. Global and regional mortality from 235 causes of death for 20 age groups in 1990 and 2010: a systematic analysis for the global burden of disease study 2010. Lancet 2012;380:2095-128.

2 Wang C, Xu J, Yang L, et al. Prevalence and risk factors of chronic obstructive pulmonary disease in China (the China Pulmonary Health [CPH] study): a national cross-sectional study. Lancet 2018;391:1706-17

3 Zhu B, Wang Y, Ming J, et al. Disease burden of COPD in China: a systematic review. Int J Chron Obstruct Pulmon Dis 2018;13:1353-64.

4 Cai B-qiang, Cai S-xi, Chen R-chang, et al. Expert consensus on acute exacerbation of chronic obstructive pulmonary disease in the people's Republic of China. Int J Chron Obstruct Pulmon Dis 2014;9:381-95.

5 Mahler DA. Peak inspiratory flow rate as a criterion for dry powder inhaler use in chronic obstructive pulmonary disease. Ann Am Thorac Soc 2017:14:1103-7.

6 Cho-Reyes S, Celli BR, Dembek C, et al. Inhalation technique errors with metered-dose inhalers among patients with obstructive lung diseases: a systematic review and meta-analysis of U.S. studies. Chronic Obstr Pulm Dis 2019;6:267-80.

7 Price DB, Román-Rodríguez M, McQueen RB, et al. Inhaler errors in the CRITIKAL study: type, frequency, and association with asthma outcomes. J Allergy Clin Immunol Pract 2017;5:1071-81.

8 Usmani OS, Lavorini F, Marshall J, et al. Critical inhaler errors in asthma and COPD: a systematic review of impact on health outcomes. Respir Res 2018;19:10.

9 López-Campos JL, Soler-Cataluña JJ, Miravitlles M. Global strategy for the diagnosis, management, and prevention of chronic obstructive lung disease 2019 report: future challenges. Arch Bronconeumol 2020;56:65-67. 
10 Sharma G, Mahler DA, Mayorga VM, et al. Prevalence of low peak inspiratory flow rate at discharge in patients hospitalized for COPD exacerbation. Chronic Obstr Pulm Dis 2017;4:217-24.

11 Ross DL, Schultz RK. Effect of inhalation flow rate on the dosing characteristics of dry powder inhaler (DPI) and metered dose inhaler (MDI) products. J Aerosol Med 1996;9:215-26.

12 Al-Showair RAM, Tarsin WY, Assi KH, et al. Can all patients with COPD use the correct inhalation flow with all inhalers and does training help? Respir Med 2007;101:2395-401.

13 Mahler DA, Waterman LA, Ward J, et al. Comparison of dry powder versus nebulized beta-agonist in patients with COPD who have suboptimal peak inspiratory flow rate. J Aerosol Med Pulm Drug Deliv 2014;27:103-9.

14 Liu D, Peng S-H, Zhang J, et al. Prediction of short term reexacerbation in patients with acute exacerbation of chronic obstructive pulmonary disease. Int $J$ Chron Obstruct Pulmon Dis 2015;10:1265-73.

15 Hu W-P, Lhamo T, Liu D, et al. Development of a nomogram to predict the risk of 30-day Re-Exacerbation for patients hospitalized for acute exacerbation of chronic obstructive pulmonary disease. COPD 2019;16:160-7.
16 Loh CH, Peters SP, Lovings TM, et al. Suboptimal inspiratory flow rates are associated with chronic obstructive pulmonary disease and all-cause readmissions. Ann Am Thorac Soc 2017;14:1305-11.

17 Mahler DA, Waterman LA, Gifford AH. Prevalence and COPD phenotype for a suboptimal peak inspiratory flow rate against the simulated resistance of the Diskus $®$ dry powder inhaler. J Aerosol Med Pulm Drug Deliv 2013;26:174-9.

18 Broeders MEAC, Molema J, Hop WCJ, et al. The course of inhalation profiles during an exacerbation of obstructive lung disease. Respir Med 2004;98:1173-9.

19 Kim V, Aaron SD. What is a COPD exacerbation? Current definitions, pitfalls, challenges and opportunities for improvement. Eur Respir J 2018;52:1801261.

20 Perpiñá Tordera M, Viejo JL, Sanchis J, et al. [Assessment of patient satisfaction and preferences with inhalers in asthma with the FSI-10 Questionnaire]. Arch Bronconeumol 2008;44:346-52.

21 Broeders MEAC, Molema J, Vermue NA, et al. In check dial: accuracy for Diskus and Turbuhaler. Int J Pharm 2003;252:275-80.

22 Atkins PJ. Dry powder inhalers: an overview. Respir Care 2005;50:1304-12. discussion 12 
Correction: Effect of PIFR-based optimised inhalation

therapy in patients recovering from acute exacerbation of

chronic obstructive pulmonary disease: protocol of a

prospective, multicentre, superiority, randomised

\section{controlled trial}

Hua J, Zhang W, Cao H, et al. Effect of PIFR-based optimised inhalation therapy in patients recovering from acute exacerbation of chronic obstructive pulmonary disease: protocol of a prospective, multicentre, superiority, randomised controlled trial. $B M J$ Open 2020;10:e034804. doi: 10.1136/bmjopen-2019-034804.

The authors want to alert readers to the following update in the published version.

On page 3 the line "Spiriva HandiHaler ( $18 \mu \mathrm{g}$ once a day) or Spiriva Respimat (2.5 $\mu \mathrm{g}$ once a day, Boehringer Ingelheim Pharma \& Co KG) will be given in combination with ICS/LABA" has been corrected to "Spiriva HandiHaler (18 $\mu$ g once a day) or Spiriva Respimat (2.5 $\mu$ g twice a day, Boehringer Ingelheim Pharma \& Co KG) will be given in combination with ICS/LABA."

Open access This is an open access article distributed in accordance with the Creative Commons Attribution Non Commercial (CC BY-NC 4.0) license, which permits others to distribute, remix, adapt, build upon this work non-commercially, and license their derivative works on different terms, provided the original work is properly cited, appropriate credit is given, any changes made indicated, and the use is non-commercial. See: http://creativecommons.org/licenses/by-nc/4.0/.

C Author(s) (or their employer(s)) 2020. Re-use permitted under CC BY-NC. No commercial re-use. See rights and permissions. Published by BMJ.

BMJ Open 2020;10:e034804corr1. doi:10.1136/bmjopen-2019-034804corr1

Check for updates 